\title{
Inovação e Comunicação de Cultura: modelos narrativos emergentes
}

Innovation and Culture Communication: models emerging narratives

Dora Santos Silva - NOVA FCSH ICNOVA - Instituto de Comunicação da NOVA dorasantossilva@fcsh.unl.pt https://doi.org/10.26619/978-989-9002-14-2.3

\begin{tabular}{|c|c|c|}
\hline Recebido / Received & Aceite / Accepted & Publicado / Published \\
14.09 .2020 & 18.09 .2020 & 15.01 .2021 \\
\hline
\end{tabular}

Como citar este capítulo / How to quote this chapter:

Santos Silva, D. (2021). "Inovação e Comunicação de Cultura: modelos narrativos emergentes". In Lourenço, J. \& P. Lopes (eds.), Comunicação, Cultura e Jornalismo Cultural (pp. 51-70). Lisboa: NIP-C@M \& UAL, disponível em https://repositorio. ual.pt/handle/11144/4751. DOI https://doi.org/10.26619/978-989-9002-14$\underline{2.3}$

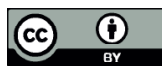




\section{Resumo}

Este capítulo explora modelos narrativos emergentes no contexto da comunicação de cultura e, em particular, no jornalismo cultural, através da análise e discussão de exemplos paradigmáticos nacionais e internacionais. $\mathrm{O}$ ecossistema digital potenciou a inovação tecnológica no setor cultural enriquecendo a experiência estética. Em alguns cenários culturais, como o dos espaços museológicos, o paradigma do objeto, que fala apenas através da sua autenticidade, foi substituído por uma narrativa imersiva, centrada na experiência do utilizador. 0 jornalismo cultural rapidamente adotou este modelo: por um lado, inova na narrativa para envolver o utilizador; por outro, centra-se cada vez mais no valor que o objeto cultural terá para o "consumidor", enquanto parte de uma experiência de consumo ou serviço, e não no valor estético do objeto em si. Quais são as principais características destes modelos narrativos? Que consequências traz para a cultura e para o jornalismo cultural? Estas são algumas questões a que o capítulo procura responder. 


\section{Abstract}

This chapter explores emerging narrative models in the context of culture communication and, in particular, in cultural journalism, through the analysis and discussion of national and international paradigmatic examples. The digital ecosystem has enhanced technological innovation in the cultural sector, enriching the aesthetic experience. In some cultural scenarios, such as museum spaces, the paradigm of the object that speaks only through its authenticity has been replaced by an immersive narrative, centered on the user's experience. Cultural journalism quickly adopted this model: on the one hand, it innovates in the narrative to engage the user; on the other hand, it increasingly focuses on the value that the cultural object will have for the "consumer", as part of a consumer or service experience, and not on the aesthetic value of the object itself. What are the main characteristics of these narrative models? What consequences does it have for culture and cultural journalism? These are some questions that the chapter seeks to answer. 


\section{Introdução}

Dizer que a digitalização do ecossistema mediático é das transformações mais significativas dos últimos anos parece ser uma verdade há muito comprovada. Porém, o ritmo esmagador das mudanças que ocorrem dessa digitalização e o impacto que tem nas várias esferas da sociedade, em particular no jornalismo e na cultura, acabam sempre por gerar um misto de surpresa (e desamparo).

A inovação nos media tem sido a consequência mais estudada. Por um lado, é apontada como uma oportunidade de as instituições culturais atraírem mais visitantes através da sua inclusão em novos paradigmas de comunicação, nomeadamente na criação colaborativa e na partilha de experiências narrativas culturais, ou de os órgãos de comunicação social conseguirem, finalmente, encontrar um modelo de negócio sustentável. Por outro, é vista como uma resposta a esse desamparo, nem sempre bem pensada, focando-se, por exemplo, naquilo a que Julie Posetti apelida de "bright, shiny things" (2018), isto é, um foco no brilho das novas tecnologias em detrimento da qualidade dos conteúdos.

Vários autores avançaram com propostas para sistematizar a inovação nos media, agrupando-as ao nível da inovação no produto, no processo, no paradigma e no posicionamento (Bleyen et al., 2014; Dogruel, 2014; Storsul and Krumsvik, 2013) e, mais recentemente, nos géneros (Krumsvik et al., 2018) (isto é, nos 
formatos usados para contar histórias), e a nível social (isto é, tendo como objetivo gerar valor social). Este capítulo explora precisamente a inovação em modelos narrativos no contexto da comunicação de cultura e, em particular, no jornalismo cultural, através da análise e discussão de exemplos paradigmáticos nacionais e internacionais. Quais são as principais características destes modelos narrativos? Que consequências trazem para a cultura e para o jornalismo cultural? Estas são algumas questões a que o capítulo procura responder, acrescentando uma breve reflexão sobre o uso dos media digitais na cultura durante a pandemia da Covid-19.

\section{O que significa comunicar cultura no século XXI?}

A comunicação de cultura engloba a partilha de informação e conhecimento relacionados com as áreas da cultura e da criatividade nos canais habituais - órgãos de comunicação social, média criativos e comunitários, e instituições culturais - e um infindável rol de websites e páginas de redes sociais. Se, antes, a comunicação de cultura era basicamente o jornalismo cultural, a transformação digital alargou esta intermediação a qualquer pessoa ou instituição que queira produzir ou partilhar conteúdo cultural. Hoje, a tecnologia está tão presente na forma como produzimos, experienciamos e partilhamos cultura que a dimensão digital se está, ela própria, a transformar num espaço público cultural (Department for Culture, Media \& Sport, 2016: 38). 
É, também, essencial termos como premissa deste capítulo a noção de que a cultura é um conceito cumulativo, que foi ganhando várias dimensões ao longo dos séculos, desde a artística (que prevalece), antropológica até à dimensão tecnológica, associada às indústrias culturais e criativas. Podemos, por isso, afirmar:

\begin{abstract}
"A cultura é um conceito heterogéneo, complexo e fluido, marcado por um campo de tensões em resultado das múltiplas definições que coexistem, particularmente entre a artística e a antropológica, a que se juntaram os novos papéis desempenhados pela cultura no ambiente industrial, económico e digital. A cultura é, assim, um conceito cumulativo: é uma manifestação artística, uma representação da vida social e do quotidiano, um serviço e um bem; é participativa, criativa, simbólica, virtual e intangível ${ }^{1 \prime \prime}$ (Santos-Silva, 2016, p. 277).
\end{abstract}

O título "o que significa comunicar cultura no século XXI?" não é original. Foi inspirado num artigo emblemático de Maggie Burnette Stogner, investigadora nas áreas do cinema e do documentário, intitulado Communicating Culture in the 21st Century: The Power of Media-Enhanced Immersive Storytelling (2011). Stogner usa uma palavra fundamental que nos guiará por este capítulo - storytelling - que, em português, pode ser traduzida

1 Tradução livre de "Culture is a heterogeneous, complex and fluid concept, marked by a field of tensions as a result of multiple definitions that co-exist, particularly the artistic and anthropological ones, to which we add the new roles that culture plays in industry, economics and digital environments. Culture is, then, an accumulative concept: it is an artistic manifestation, a representation of social life and everyday life, a service and a good, it is participatory and creative, symbolic, virtual and an intangible good". 
como a estratégia utilizada para contar uma história, isto é, uma técnica ou modelo narrativo. São estes modelos narrativos que nos interessa desconstruir.

\section{Evolução dos paradigmas de modelos narrativos}

Casero-Ripollés et al. (2020) definem storytelling como

"um conjunto de técnicas e estratégias utilizadas para contar ou partilhar uma história com o objetivo de adicionar valor às notícias e gerar interesse no público. Permite o uso e combinação de qualquer tipo de linguagem e formato do ambiente digital (texto, imagem, vídeo, áudio, gráficos, etc.) para construir uma história com uma estrutura narrativa que seja apelativa à audiência"² (p. 72)

Esta é uma definição que encaixa bem no ecossistema ideal, dado que é incontornável a utilização do potencial dos formatos digitais para inovar nos modelos narrativos.

A primeira grande ruptura nos modelos narrativos contemporâneos - caracterizados por um princípio, meio e fim e cuja experiência do utilizador obedecia a essa linearidade - foi precisamente com a linearidade da história. Aliás, a história poderia continuar a ter um princípio, meio e fim ou vários princípios,

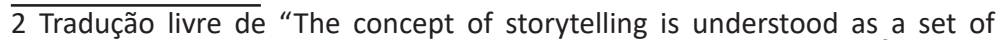
techniques and strategies used to tell and share a story with the goal of creating added value to the news and generating public interest. It allows the use and combination of any type of language and format of the digital environment (text, image, video, audio, graphics, etc.) to build a story with a full narrative structure that is attractive to the audience". 
meios e fins, consoante a experiência de navegação do utilizador. A hipertextualidade, a multimedialidade e a interatividade surgiram como formatos fundamentais para adicionar valor às histórias.

Nas narrativas multimédia, cuja não-linearidade é uma das suas características fundamentais, cada formato é usado de acordo com o valor que pode acrescentar à história: "uma estória multimédia é uma combinação de texto, fotografias, vídeo, áudio, gráficos e interatividade presente num website num formato não-linear onde a informação que cada medium traz é complementar, não redundante ${ }^{3 \prime \prime}$ (Jane Stevens, 2014, para. 2).

O paradigma da narrativa multimédia do jornalismo, identificado como o "the snow fall effect", nasceu com uma peça do The New York Times, publicada em dezembro de 2012, intitulada Snow Fall: The Avalanche at Tunnel Creek $^{4}$ (uma peça que envolveu 16 profissionais, desde jornalistas a designers multimédia). Acabaria por arrecadar o prémio Pulitzer em 2013 na categoria "feature writing", precisamente pelo enriquecimento da história através dos elementos multimédia. Neste caso, a inovação neste modelo narrativo derivava da integração de vídeo, fotografia e infografias não como acessórios do texto, mas com uma função muito específica na narrativa. $\mathrm{O}$ vídeo sem som posicionava o utilizador no cenário, o vídeo com som dava conta dos testemu-

3 Tradução livre de "A multimedia story is some combination of text, still photographs, video clips, audio, graphics and interactivity presented on a website in a nonlinear format in which the information in each medium is complementary, not redundant".

4 Disponivel em http://www.nytimes.com/projects/2012/snowfall/\#/?part=tunnel-creek (acedido a 10 de agosto de 2020) 
nhos das pessoas, as infografias explicavam o processo que motivou a avalanche, as galerias de imagem davam contexto, isto é, estes elementos não eram usados de forma aleatória.

Outro paradigma fundamental na evolução dos modelos narrativos na cultura foi o de transmedia storytelling ou narrativas transmediáticas, introduzido por Henry Jenkins, em 2003. O que diferencia este modelo é o desdobramento de uma história por várias unidades distribuídas por plataformas mediáticas: cada unidade tem sentido por si só, mas contribui também para o enriquecimento da história original.

"Na forma ideal de uma narrativa transmediática, cada medium faz o que faz melhor - uma história pode ser introduzida num filme, expandir-se através da televisão, romances, banda desenhada, e o seu mundo pode ser explorado e experienciado através de jogos. Cada franchise precisa de ter independência suficiente para permitir um consume autónomo. Isto é, não é necessário ver o filme para apreciar o jogo e vice-versa ${ }^{5}$." (2003: 10)

No campo da cultura, as narrativas transmediáticas têm sido muito exploradas, por exemplo, no cinema e séries de televisão. Game of Thrones (2011-2019) foi uma série produzida pela HBO, com base na obra literária de George R. R. Martin, que se expan-

5 Tradução livre de "In the ideal form of transmedia storytelling, each medium does what it does best-so that a story might be introduced in a film, expanded through television, novels, and comics, and its world might be explored and experienced through game play. Each franchise entry needs to be selfcontained enough to enable autonomous consumption. That is, you don't need to have seen the film to enjoy the game and vice-versa." 
diu para videojogos, jogos de tabuleiro, redes sociais e outros projetos promovidos pela própria comunidade de fãs.

Daqui até ao modelo narrativo imersivo foi um pulo. Em 2010, Nonny de la Peña et al. já tinham proposto uma definição de jornalismo imersivo na qual se relevava a oportunidade de colocar o utilizador "dentro" da narrativa: "a produção de notícias numa forma na qual o utilizador pode ganhar uma experiência na primeira pessoa de eventos ou situações descritas nas peças jornalísticas" (2010: 291). Nos 10 anos seguintes, as narrativas imersivas, em particular o jornalismo imersivo, viriam a beneficiar do progresso nas áreas do vídeo e da tecnologia digital. Hoje, as grandes promessas do jornalismo imersivo são a realidade aumentada e a realidade virtual, porque ambas permitem o envolvimento do utilizador de "uma forma não convencional, posicionando-o num determinado tempo e espaço" (Vázquez-Herrero et al., 2020: 34). O primeiro tipo de realidade decorre num espaço exclusivamente virtual, ao passo que a realidade aumentada conjuga os espaços real e virtual.

No campo do jornalismo, o The New York Times tem sido um dos media internacionais a apostarem mais na realidade virtual e aumentada. Várias peças com recurso a estes formatos estão disponíveis na sua app, na secção "Immersive (AR/VR)" (à data de setembro de 2020).

No campo da cultura, em particular dos museus, os media imersivos são uma forma de dar contexto aos objetos reais e criar 
conteúdos. A realidade virtual tem sido usada sobretudo para visitas virtuais ao espólio e a aumentada para acrescentar contexto aos objetos. Para Stogner (2011) as novas técnicas narrativas servem, essencialmente, para envolver os visitantes na experiência da visita ao museu. A investigadora identificou cinco tipos de modelos narrativos imersivos nos museus que continuam atuais em 2020 e que podem, na verdade, ser adequados a qualquer área dos media e da cultura:

- Na imersão experiencial, a imersão na narrativa é baseada apenas na experiência estética ou em sensações, como contemplar um espaço ou absorver a atmosfera do interior de um edifício histórico.

- Na imersão narrativa, a imersão é baseada numa experiência narrativa, isto é, um argumento e personagens que contextualizam objetos. Aqui é vulgar usar media imersivos para criar uma sensação de tempo, espaço e percurso.

- Na imersão performativa (ou teatral), muito comum em centros científicos, o utilizador beneficia da realidade virtual, aumentada e outras funcionalidades 3D para experienciar elementos multissensoriais como o vento, a neve, cheiros ou sabores.

- Na imersão interativa, a imersão foca-se na interação que o utilizador poderá ter, quer no próprio espaço físico, quer no virtual, através de visitas com conteúdos georreferenciados, por exemplo, ou na interação com a comunidade do museu. 
- Na imersão virtual, o utilizador é levado a um tempo e espaço exclusivamente virtual através da realidade virtual, videojogos e outros formatos digitais.

Por fim, a estes modelos narrativos acrescentaria outros dois que, embora tenham existido desde sempre, foram potenciados pelo ambiente digital nos últimos anos. Ao primeiro chamaria de micronarrativas fragmentadas. Estas são caracterizadas por fluxos de conteúdo que se disseminam pelas redes sociais e que dificilmente se controlam - quer no seu todo quer na sua origem. As micronarrativas fragmentadas - que podem incluir desde comentários sobre um determinado assunto no twitter a uma estratégia articulada de disseminação de uma determinada narrativa - estão associadas hoje a uma realidade incontornável do ecossistema digital, que ainda não se conseguiu ultrapassar: a desinformação tão visível na arquitetura de conteúdos de movimentos políticos, populistas e nos discursos de ódio.

Ao segundo chamaria de narrativas de proximidade, associadas ao fenómeno da cultura de proximidade. A cultura de proximidade baseia-se na ligação de pessoas com base nos motivos que levam a essa proximidade, seja partilharem um local de residência seja partilharem gostos ou formas de estar. A cultura de proximidade está também relacionada com a inclusão social, dirigindo-se a grupos que partilham um legado cultural e social (como refugiados ou minorias étnicas). Por sua vez, as narrativas de proximidade baseiam-se no que une as pessoas. Um dos exemplos mais claros é trazido pelos media comunitários que se focam na cobertura de acontecimentos locais (numa freguesia, 
bairro ou numa região), ou num nicho de utilizadores (amantes da música clássica ou da cultura de tatuagens). Essas narrativas são desenvolvidas em especial para esse público e não para um público em geral.

Narrativas multimédia, transmédia e imersivas. Hoje, há tantos formatos a explorar que se torna complexo analisar todos os modelos narrativos. O próximo ponto desconstrói alguns na área da comunicação de cultura e, em particular, no jornalismo cultural.

\section{Sete modelos e formatos narrativos emergentes}

Em 2020, estes eram sete dos modelos narrativos mais usados na comunicação de cultura e no jornalismo cultural. É essencial realçar que a maior parte dos exemplos contemplados tem elementos de vários formatos narrativos, dado que o hibridismo é uma característica incontornável das narrativas contemporâneas.

\section{Narrativas de proximidade}

Como explicado no ponto anterior, estas narrativas baseiam-se no conceito de ligação que une os utilizadores, que pode ser motivada pela proximidade geográfica, cultural, afetiva, social, entre outros tipos. O projeto Mygrantour ${ }^{6}$ oferece passeios interculturais pelas cidades que fazem parte da rede (16 em 2020,

6 Uma rede europeia do migrante impulsionando rotas culturais para compreender a diversidade cultural é um exemplo dessa proximidade social, disponível em http://www.mygrantour.org/pt-pt/. 
incluindo Lisboa), mas os guias são migrantes, isto é, a descoberta das cidades por pessoas que as visitam é feita com a ajuda de guias que migraram para essas cidades, ou seja, as cidades também Ihes eram desconhecidas.

Outros exemplos de narrativas de proximidade são aquelas publicadas por órgãos de comunicação social que apostam numa cobertura local ou numa cobertura de nicho, como a revista Gerador ${ }^{7}$. Também os media comunitários - projetos que não são órgãos de comunicação social, mas que prestam informação relevante com uma abordagem jornalística para as suas comunidades - têm espaço aqui. Os projetos editoriais Coffeepaste ${ }^{8}$ e Rosa Maria (um jornal impresso sobre o bairro da Mouraria) cumprem este objetivo de proximidade.

\section{Narrativas colaborativas}

Estas narrativas são criadas a partir do contributo de vários utilizadores a uma escala local ou até internacional. Um exemplo internacionalmente reconhecido é o Historypin ${ }^{9}$ que liga comunidades de todo o mundo através de histórias locais, que estão organizadas por temas ou espaços geográficos. Por exemplo, a coleção "First World War Centenaries"10 tinha reunido até setembro de 2020 mais de oito mil contributos visuais de comu-

\footnotetext{
7 Disponível em: $\underline{\text { http://gerador.eu }}$

8 Disponível em: https://coffeepaste.com/.

9 Disponível em: https://www.historypin.org/en/.

10 Disponível em: https://www.historypin.org/en/first-world-war-centenary/ geo/54.42697,-2.310991,6/bounds/48.401913,-7.049577,59.680265,2.427595/ paging/1
} 
nidades de todo o mundo. O projeto recorre a vários formatos multimédia e a conteúdos georreferenciados utilizando o google maps.

Outro exemplo de projeto colaborativo bem original é o de Little Museum of Dublin ${ }^{11}$. Em 2011, o então futuro museu pediu aos habitantes da cidade que doassem objetos que contassem a história de Dublin. O acervo conta hoje com cinco mil artefatos.

\section{Narrativas georreferenciadas e glocalizadas}

Os roteiros culturais - importante estratégia narrativa no turismo que toma como objeto a cultura - têm também evoluído muito com a crescente integração do áudio, de conteúdos georreferenciados e glocais, isto é, conteúdos locais que contribuem para uma cultura global. As apps de visitas a cidades, que sugerem roteiros com base nos gostos ou objetivos dos utilizadores ou que Ihes permitem personalizar visitas, pululam no App Store ou na Google Play Store (basta digitar "visita guiada" no campo de pesquisa). Em Portugal, o projeto $F C S H+L_{i s b o a^{12}}$ cria roteiros temáticos e geográficos com base na produção científica sobre a cidade.

\section{Narrativas baseadas em formatos de vídeo, áudio ou multimédia}

O vídeo nos seus vários formatos (como o social video, live video, vídeos 360 graus) ou o áudio - em grande parte devido aos

11 Disponível em: https://www.littlemuseum.ie/.

12 Disponível em: http://maislisboa.fcsh.unl.pt. 
podcasts - tiveram uma evolução marcante nos últimos anos, quer no jornalismo cultural, quer na comunicação de cultura a nível global. São raros os museus que não oferecem vídeos, audioguias ou suportes multimédia aos seus visitantes. Neste campo, merece destaque a Culturespaces ${ }^{13}$, uma agência privada francesa que gere, entre outras iniciativas, 14 websites de museus e centros de arte em França com uma grande componente multimédia. Em 2018, lançou um centro de arte digital em Paris - Atelier des Lumiéres - onde promove exposições imersivas com recurso ao videomapping e a outras funcionalidades 3D.

Nas áreas das artes performativas, grandes companhias de teatro, música e ópera disponibilizam nos seus websites a possibilidade de assistir a peças em streaming. No áudio, além dos inúmeros podcasts dedicados à cultura, alguns projetos têm explorado as potencialidades do som com recurso ao binaural ou ao audiomapping. Os postais sonoros de Lisboa, que registam os sons da cidade durante a pandemia, ou os sons de bairros históricos de Lisboa são algumas das iniciativas do projeto de investigação Sounds of Tourism ${ }^{14}$, coordenado pelo antropólogo Iñigo Sanchez.

No jornalismo, os formatos multimédia têm sido objeto de imensuráveis peças. Uma das mais vistas em 2019 foi a peça multimédia An illustrated guide to all 6,887 deaths in 'Game of Thrones ${ }^{15}$, publicada pelo The Washington Post em 2019, que

13 Disponível em: https://www.culturespaces.com/.

14 Disponível em: http://www.soundsoftourism.pt/.

15 Disponível em https://www.washingtonpost.com/graphics/entertainment/ game-of-thrones/ 
conjuga dados, ilustração, hipertexto e conteúdos georreferenciados para mostrar as 6.887 mortes mortes que existiram nas oito temporadas desta célebre série.

\section{Narrativas transmediáticas}

No ponto 2 deste capítulo, já foi dado um exemplo de narrativa transmediática - a Guerra dos Tronos -, mas as indústrias culturais estão repletas de outros, desde os heróis da Marvel ou da DC Comics que se expandem para o cinema, videojogos e séries de televisão, aos heróis do entretenimento infantil no YouTube, como o fenómeno português Panda e os Caricas, que se expandiram para concertos, material educativo e um sem-número de artigos de merchandising.

\section{Narrativas baseadas em dados, interação ou gamifica- das}

Estas narrativas baseiam-se em dados complexos que são depois apresentadas sob a forma de infografias, jogos ou experiências interativas. What was Leonardo da Vinci doing at your $a g e^{16}$, peça criada pela CNN para a comemoração do 500 aniversário da morte do artista e vencedora de um Webby Award em 2020, na categoria "Arts", é disso exemplo. O utilizador entra num microsite e regista a sua idade. Automaticamente, surge um texto sobre o que Leonardo da Vinci estava a fazer com a idade do utilizador. Outro exemplo é dado pelo Spotify, platafor-

16 Disponível em https://edition.cnn.com/interactive/style/leonardo500/ 
ma de áudio, que no final de cada ano oferece aos ouvintes uma série de dados com base nas suas preferências ao longo desse ano: as músicas, géneros e artistas mais ouvidos e outros conteúdos lúdicos. A iniciativa é conhecida como Spotify Wrapped ${ }^{17}$.

\section{Narrativas imersivas}

São incluídas neste modelo as narrativas que recorrem à realidade virtual, aumentada ou a funcionalidades 3D. Para explorar estes formatos em museus de todo o mundo, o ponto de encontro privilegiado é a iniciativa Google Arts \& Culture. No campo dos roteiros culturais, a aplicação Rewind Cities (disponível na Google Play Store, App Store e Samsung apps), que já inclui Lisboa e Porto, usa a realidade aumentada para mostrar como eram determinados locais das cidades no passado. Basta apontar o telemóvel para os locais georreferenciados e aceder a imagens do passado daquele preciso local.

A pandemia da Covid-19, que exigiu o encerramento de atividades e instituições culturais dirigidas ao público em espaços físicos em 2020, levou a um aproveitamento das potencialidades do ambiente digital, principalmente o vídeo e o áudio. Provocou o aumento das visitas a museus em todo o mundo, promoveu tertúlias e debates, viu nascer concertos e peças de teatro para ouvir e ver, mas tudo isto sem sair de casa, graças às plataformas digitais. Foram tempos de (ainda mais) precariedade para os profissionais das artes e cultura, mas também uma oportuni-

17 Disponível em https://www.spotify.com/pt/wrapped/ 
dade para encontrar novos públicos e envolvê-los sem a restrição do espaço físico. Desde o Royal Opera House em streaming ao Como é que o Bicho Mexe, apresentado por Bruno Nogueira e com transmissão diária no Instagram, a pandemia também contribuiu para a democratização da cultura e alargou o acesso a estas iniciativas. Pelo menos, de quem tem acesso às plataformas digitais.

\section{Bibliografia}

Bleyen, V., Lindmark, S., Ranaivoson, H. \& Ballon, P. (2014). A typology of media innovations: Insights from an exploratory study. The Journal of Media Innovations, 1(2014), pp. 28-51, disponível em: https:// www.journals.uio.no/index.php/TJMI/issue/view/83. (Acedido a 2 de agosto de 2020).

Casero-Ripollés et al. (2020). New Formats for Local Journalism in the Era of Social Media and Big Data: From Transmedia to Storytelling. In Vázquez-Herrero, J., Direito-Rebollal, S., Silva-Rodríguez, A. \& LópezGarcía, J. (editors), Journalistic Metamorphosis: Media Transformation in the Digital Age. Cham: Springer, pp.69-84.

De la Peña, N., Weil, P., Llobera, J., Giannopoulos, E., Pomés, A., Spanlang, B., \& Slater, M. (2010). Immersive journalism: immersive virtual reality for the first-person experience of news. Presence: Teleoperators and virtual environments, 19(4), pp. 291-301. Acedido a 1 de agosto de 2020 em https://www.mitpressjournals.org/doi/ abs/10.1162/PRES_a_00005.

Department for Culture, Media \& Sport (2016). The Culture White Paper. UK. Web ISBN 9781474129329.

Dogruel, L. (2014). "What is so Special about Media Innovations? A Characterization of the Field.", The Journal of Media Innovations 1, pp. 52-69. Acedido a 1 de agosto de 2020 em https://www.journals.uio. no/index.php/TJMI/issue/view/83. 
Jenkins, H. (2003). Transmedia Storytelling. MIT Technology Review. Availabel in: em https://www.technologyreview. com/2003/01/15/234540/transmedia-storytelling/ (Acedido a $4 \mathrm{de}$ agosto de 2020).

Krumsvik, A. H., Milan, S., Bhroin, N. N., \& Storsul, T. (2018). Making (Sense of) Media Innovations. In M. Deuze \& M. Prenger (Eds.), Making media: production, practices and professions, pp. 193-205. Amsterdam: Amsterdam University Press.

Posetti, J. (2018). Time to step away from the 'bright, shiny things'? Towards a sustainable model of journalism innovation in an era of perpetual change. [Report] Reuters Institute for the Study of Journalism, available in: https://reutersinstitute.politics.ox.ac.uk/sites/default/ files/2018-11/Posetti Towards a Sustainable model of Journalism FINAL.pdf (Acedido a 1 de agosto de 2020).

Santos Silva, D. (2016). Cultural Journalism in a Digital Environment: New Models, Practices and Possibilities. Tese de Doutoramento. Universidade Nova de Lisboa, UT Austin | Portugal CoLab, available in: https://run.unl.pt/handle/10362/17022 (Acedido a 3 de agosto de $2020 \mathrm{em})$.

Stogner, M. (2011). Communicating Culture in the $21^{\text {st }}$ Century. Journal of Museum Education, (2011), 36(2), pp. 189-198.

Stevens, J. (2014). Multimedia Storytelling: Learn The Secrets From Experts, available in: http://multimedia.journalism.berkeley.edu/ tutorials/starttofinish/ (Acedido a 1 de agosto de 2020).

Storsul, T., \& Krumsvik, A. H. (2013). What is Media Innovation? In Media Innovations. A Multidisciplinary Study of Change, pp. 13-26. Gothenburg: Nordicom.

Vázquez-Herrero, J., López-García, X., \& Irigaray, F. (2020). The Technology-Led Narrative Turn. In J. Vázquez-Herrero, S. DireitoRebollal, A. Silva-Rodríguez, \& X. López-García, Journalistic Metamorphosis. Media Transformation in the Digital Age, pp. vii-ix. Cham: Springer. 